\title{
Photocatalytic Synthesis of Gold Nanoparticles Using Preyssler Acid and Their Photocatalytic Activity
}

\author{
Ali AYATI ${ }^{1}$, Ali AHMADPOUR ${ }^{1, *}$, Fatemeh F. BAMOHARRAM ${ }^{2}$, Majid M. HERAVI ${ }^{3}$, Hamed RASHIDI ${ }^{1}$ \\ ${ }^{1}$ Department of Chemical Engineering, Ferdowsi University of Mashhad, Mashhad, Iran \\ ${ }^{2}$ Department of Chemistry, School of Sciences, Islamic Azad University, Mashhad Branch, Mashhad, Iran \\ ${ }^{3}$ Department of Chemistry, School of Sciences, Alzahra University, Tehran, Iran
}

\begin{abstract}
Preyssler acid $\mathrm{H}_{14}\left[\mathrm{NaP}_{5} \mathrm{~W}_{30} \mathrm{O}_{110}\right]$ was used as reducing agent and stabilizer for the synthesis of gold nanoparticles by photolysis of $\mathrm{Au}(\mathrm{III}) /$ Preyssler acid/propan-2-ol solution. Preyssler acid plays both the role of transferring electrons from propan-2-ol to Au(III) and stabilizing the nanoparticles. Propan-2-ol was used as sacrificial reagent for the photoformation of reduced Preyssler acid. Gold nanoparticles (Au NPs) were characterized by UV-Vis spectroscopy, transmission electron microscopy (TEM), and particle size distribution (PSD) measurements. The synthesized Au NPs had a uniform hexagonal morphology and their size was about $17 \mathrm{~nm}$. The catalytic performance of these NPs for photodegradation of methyl orange (MeO) was investigated in aqueous solution. UV-Vis studies showed that Au NPs can catalyze photodegradation of this azo dye. The pseudo-first-order rate constants were also calculated for this reaction.
\end{abstract}

Key words: gold; nanoparticle; polyoxometalate; Preyssler acid; photodegradation; methyl orange

CLC number: O643 Document code: A

Received 14 December 2010. Accepted 14 March 2011.

*Corresponding author.Tel: +98-511-8816840; Fax: +98-511-8816840; E-mail: ahmadpour@um.ac.ir

This work was supported by the Faculty of Engineering, Ferdowsi University of Mashhad, through the grant 13198.

English edition available online at Elsevier ScienceDirect (http://www.sciencedirect.com/science/journal/18722067).

The applications of polyoxometalate compounds have attracted much attention particularly in the last two decades [1]. Polyoxometalates (POMs) are a class of molecularly defined inorganic metal-oxide clusters, which possess intriguing structures and diverse properties [2]. Their structures remain unchanged when subjected to stepwise and multielectron redox reactions and these compounds can be reduced by electrochemical and photochemical procedures using suitable reducing reagents $[3,4]$. These properties encourage researchers to use them in the synthesis of metal nanoparticles (NPs) using simple, efficient, and ambient temperature methods [5,6]. A wide range of applications have been reported for metal nanoparticles. Among them, gold nanoparticle have various applications in catalysis, electronics, sensors, medicine, etc. [7,8].

There are many reports describing the synthesis of $\mathrm{Au}$ nanoparticles using POMs [9-12]. Mandal et al. [9] and Troupis et al. [10] demonstrated that several metal ions $\left(\mathrm{Ag}^{+}, \mathrm{Pd}^{2+}, \mathrm{Au}^{\mathrm{III}}\right.$, and $\left.\mathrm{Pt}^{\mathrm{IV}}\right)$ could form metal nanoparticles in the presence of photochemically reduced Keggin heteropolyanions $\left[\mathrm{SiW}_{12} \mathrm{O}_{40}\right]^{5-}$ and $\left[\mathrm{PW}_{12} \mathrm{O}_{40}\right]^{4-}$ as photocatalysts, using mild reductants and stabilizers in a simple process. Mandal and coworkers [11] reported that photochemically generated $\left[\mathrm{PW}_{12} \mathrm{O}_{40}\right]^{4}$ capped gold nanoparticles facilitate the reduction of $\mathrm{Ag}^{+}$on the surface of gold nanoparticles to form $\mathrm{Au}-\mathrm{Ag}$ core-shell bimetallic NPs at room temperature under UV irradiation. In another study, Au nanoparticles were prepared via a simple photoreduction technique in the presence of transition metal-monosubstituted Keggin heteropolyanions $\left(\mathrm{PW}_{11} \mathrm{MO}_{40}, \mathrm{M}=\mathrm{Cu}^{2+}, \mathrm{Ni}^{2+}, \mathrm{Zn}^{2+}, \mathrm{Fe}^{3+}\right)$ as reducing agent, a photocatalyst, and a stabilizer [12].

Although Keggin and mixed-valance types of POMs have been used in the synthesis of Au nanoparticles, the Preyssler acid structure has been largely overlooked. This heteropolyacid is remarkable because of the following advantages: (1) strong Brönsted acidity with 14 acidic protons, (2) high thermal stability, (3) high hydrolytic stability $(\mathrm{pH}$ $0-12$ ), (4) reusability, (5) safety, (6) quantity of waste, (7) separability, (8) non-corrosiveness, (9) high oxidation potential, and (10) environmental friendliness [13]. According to the principles proposed for green chemistry, Preyssler acid is a promising candidate as a green material. This heteropolyanion is green with respect to corrosiveness, safety, quantity of waste, and separability. In recent years a series of catalytic reactions using Preyssler acid have been studied in our group [14-17].

In the present work, we have used Preyssler acid to synthesize gold nanoparticles via a simple photoreduction technique. Preyssler acid plays both roles of photocatalytic reducing agent and stabilizer. To the best of our knowledge, 
the synthesis of nanoparticles has not been investigated using Preyssler acid. The performance of these Au nanoparticles for photodegradation of methyl orange $(\mathrm{MeO})$ was also explored.

\section{Experimental}

\subsection{Synthesis of Au nanoparticles}

In a typical experiment $5 \mathrm{ml}$ of an aqueous solution of Preyssler acid, $\mathrm{H}_{14}\left[\mathrm{NaP}_{5} \mathrm{~W}_{30} \mathrm{O}_{110}\right]\left(6.7 \times 10^{-7} \mathrm{~mol} / \mathrm{L}\right.$, prepared according to Refs. [18-20]), $10 \mathrm{ml} \mathrm{HAuCl}_{4}$ (1 $\mathrm{mmol} / \mathrm{L}, \mathrm{AR}, \mathrm{Merck}$ ), and $2 \mathrm{ml}$ propan-2-ol (AR, Merck) were placed into a spectrophotometer cell and deaerated with $\mathrm{N}_{2}$ gas. Then the mixture was irradiated by UV light (125 W high pressure mercury vapor lamp) for $45 \mathrm{~min}$ under continuous stirring. The reaction was performed at constant room temperature with water circulating around the cell. The color of the solution changed from colorless to pink, indicating the formation of Au nanoparticles [12]. The nanoparticles were separated by a high speed centrifuge. After centrifugation the NPs were separated and then washed several times (at least two times) by water. In the washing stage the Preyssler acid is dissolved in the water and only Au NPs remained.

\subsection{Typical procedure for photocatalytic degradation of $\mathrm{MeO}$}

The photoreactor used for the synthesis of nanoparticles and also photocatalytic degradation experiments was designed in our laboratory. In a typical reaction, $25 \mathrm{ml}$ of $\mathrm{MeO}$ solution $(30 \mu \mathrm{mol} / \mathrm{L}), 5 \mathrm{ml}$ hydrogen peroxide, and $1.5 \mathrm{ml}$ aqueous $\mathrm{Au}$ nanoparticles $(0.005 \mathrm{~mol} / \mathrm{L})$ were mixed in a quartz glass equipped with a magnetic stirrer. The mixture was stirred and purged with nitrogen for $1 \mathrm{~h}$ and then it was irradiated under a high pressure mercury vapor lamp (125 W) as UV light source at constant temperature of $25^{\circ} \mathrm{C}$. At given irradiation time intervals liquid samples were taken from the mixture and the absorbance of the $\mathrm{MeO}$ solution were measured with a UV-Vis spectrophotometer.

\subsection{Characterization of Au nanoparticles}

The prepared $\mathrm{Au}$ nanoparticles were characterized mainly by its particle size distribution using a laser particle sizer (ZetaSizer Nano ZS apparatus, Malvern Instruments Ltd.). The instrument allowed to measure particle size taking advantage of optoelectronic systems. The nanoparticles were also characterized using transmission electron microscopy (TEM, PHILIPS CM-120). UV-Vis spectra were obtained using an Agilent 8453 single beam instrument.

\section{Results and discussion}

The applied method was a one pot synthesis technique for $\mathrm{Au}$ NPs preparation, which is simple and efficient and takes place within a short time at ambient temperature. Using Preyssler acid $\mathrm{H}_{14}\left[\mathrm{NaP}_{5} \mathrm{~W}_{30} \mathrm{O}_{110}\right]$ as a reducing agent and stabilizer, the synthesis of gold NPs by photolysis of a $\mathrm{Au}(\mathrm{III}) /$ Preyssler acid/propan-2-ol solution was carried out. Preyssler acid plays the role of transferring electrons from propan-2-ol to $\mathrm{Au}(\mathrm{III})$ and also stabilizing the nanoparticles. To help and speed up the reaction of Preyssler acid with $\mathrm{Au}(\mathrm{III})$, propan-2-ol was used as sacrificial reagent.

\subsection{Possible reaction mechanism}

According to Refs. [4,5,21], POMs become powerful oxidants for a great variety of organic compounds under excitation of the $\mathrm{O} \rightarrow \mathrm{M}$ charge transfer band (UV and near visible region). The reduced form of POMs is a powerful reducing reagent, which can be easily reoxidized by a diverse number of chemicals including metal ions, i.e. $\mathrm{Ag}^{+}$, $\mathrm{Pd}^{2+}$, or $\mathrm{Au}^{3+}$. This results in closing the photocatalytic cycle in the presence of an organic substrate (S), i.e. alcohols or various organic pollutants, according to the following reactions $[5,10,22]$ :

$$
\begin{aligned}
& \mathrm{POM}+\mathrm{S} \stackrel{\mathrm{h} v}{\longrightarrow} \mathrm{POM}\left(\mathrm{e}^{-}\right)+\mathrm{S}_{\mathrm{OX}} \\
& \mathrm{POM}\left(\mathrm{e}^{-}\right)+\mathrm{Au}^{3+} \rightarrow \mathrm{POM}+\mathrm{Au}^{0}
\end{aligned}
$$

According to their findings [5,10], synthesis of Au NPs with reasonably small size distribution could be achieved (Reaction (3), $\mathrm{Au}_{\text {coll }}^{0}=$ colloidal Au metal).

$$
\mathrm{POM}\left(\mathrm{e}^{-}\right)+\mathrm{Au}^{3+} \rightarrow \mathrm{POM}+\mathrm{Au}_{\text {coll }}^{0}
$$

Reactions (1) and (3) may be separated in time and space (two pot systems), or occur in a one pot system, where the POM plays the double role of photocatalytic reducing agent and stabilizer. In this study, a colloidal solution of nanoparticles of $\mathrm{Au}^{0}$ was formed by photocatalytic reduction of $\mathrm{Au}(\mathrm{III})$ in the presence of Preyssler acid, $\mathrm{H}_{14}\left[\mathrm{NaP}_{5} \mathrm{~W}_{30} \mathrm{O}_{110}\right]$ as a POM. Also, propan-2-ol plays the role of sacrificial agent as an organic substrate (S).

These nanoparticles were apt to aggregate and precipitate in the solution due to their typical hydrophobic surface properties. In the absence of Preyssler acid, $\mathrm{Au}^{0}$ particles were precipitated after $2 \mathrm{~d}$, but the resulting colloid was stable without any precipitating for several weeks in the presence of Preyssler acid. Even if the precipitation happened, the Au NPs could be easily redispersed by simple shaking. These observations indicate the stabilizing role of Preyssler acid in this reaction. It might be due to the POM polyanions adsorbing onto the surface of Au NPs which provides both kinetic stabilization through coulombic repulsion between negatively charged particles and also steric 
stabilization [23].

An experiment in the absence of UV irradiation showed that the formation of nanoparticles is very slow and it takes more than $6 \mathrm{~h}$. Also, in the absence of the Preyssler acid, nanoparticles were synthesized only after more than 150 min. As shown in Fig. 1, the intensity of peak (2) is higher than (3) indicating that the preparation of nanoparticles is faster using Preyssler acid.

\subsection{Characterization}

Figure 1 shows UV-Vis absorption spectra of solutions before and after photosynthesis of gold NPs. Before irradiation, there is no distinct absorption band in the wavelength range of 400-800 nm. However, as shown in Fig. 1(2), after UV light irradiation for $45 \mathrm{~min}$ the UV-Vis spectrum shows an SPR band of gold NPs at $530 \mathrm{~nm}$. Also, changing the color of the solution from colorless to pink is an indication of gold NP formation.

The gold nanoparticles obtained were characterized by TEM. Representative TEM images are shown in Fig. 2. The shapes of the gold nanoparticles obtained are nearly uniform

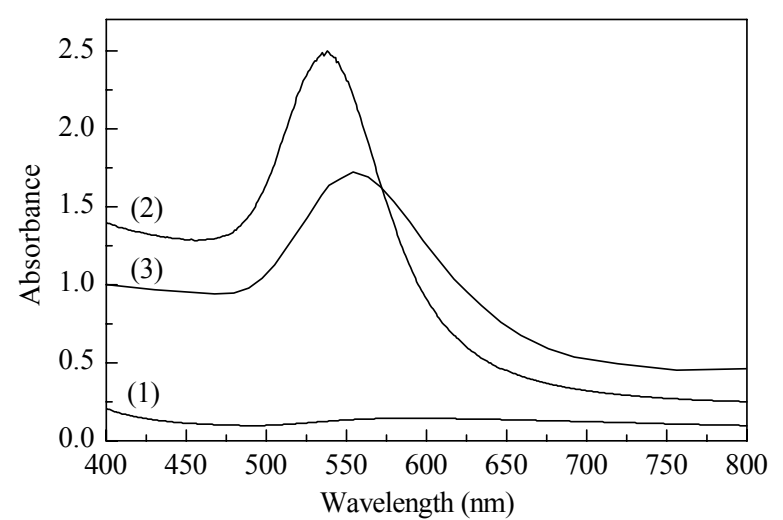

Fig. 1. UV-Vis spectra of Au NPs solutions. (1) Before irradiation; (2) After irradiation for $45 \mathrm{~min}$ in the presence of Preyssler acid; (3) After irradiation for $150 \mathrm{~min}$ in the absence of Preyssler acid.

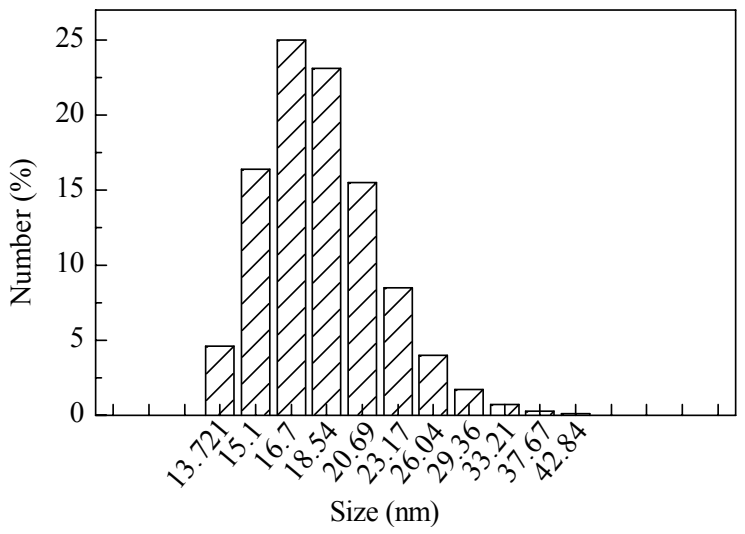

Fig. 3. Particle size distribution of Au NPs after 45 min irradiation.

hexagonal structures. The particle size distribution of the synthesized Au nanoparticles is quantitatively displayed in a histogram shown in Fig. 3. As can be seen, the particle size distribution indicated that the size of the synthesized $\mathrm{Au}$ nanoparticles varied from about $13 \mathrm{~nm}$ to $43 \mathrm{~nm}$, but most of them are about $17 \mathrm{~nm}$ large.

Usually there is a tendency of agglomeration via Coulomb or van der Waals forces in the synthesis process of nanoparticles. Preyssler acid is an excellent stabilizer to prevent agglomeration. Also, Preyssler acid is easily separated after the reaction and will not contaminate the gold nanoparticles.

Propan-2-ol serves as sacrificial reagent for the photoformation of one-equivalent reduced Preyssler acid, $\operatorname{POM}\left(\mathrm{e}^{\top}\right)$, which further reacts with $\mathrm{Au}(\mathrm{III})$ to produce gold nanoparticles. We have observed that when the amount of propan-2-ol was less than $1 \mathrm{ml}$, there was not any color change and no gold NPs were obtained.

\subsection{Effect of Preyssler acid concentration}

The effect of Preyssler acid concentration was investigated in our study. Based on both roles of Preyssler acid as a reducing agent and stabilizer, it could be concluded that by
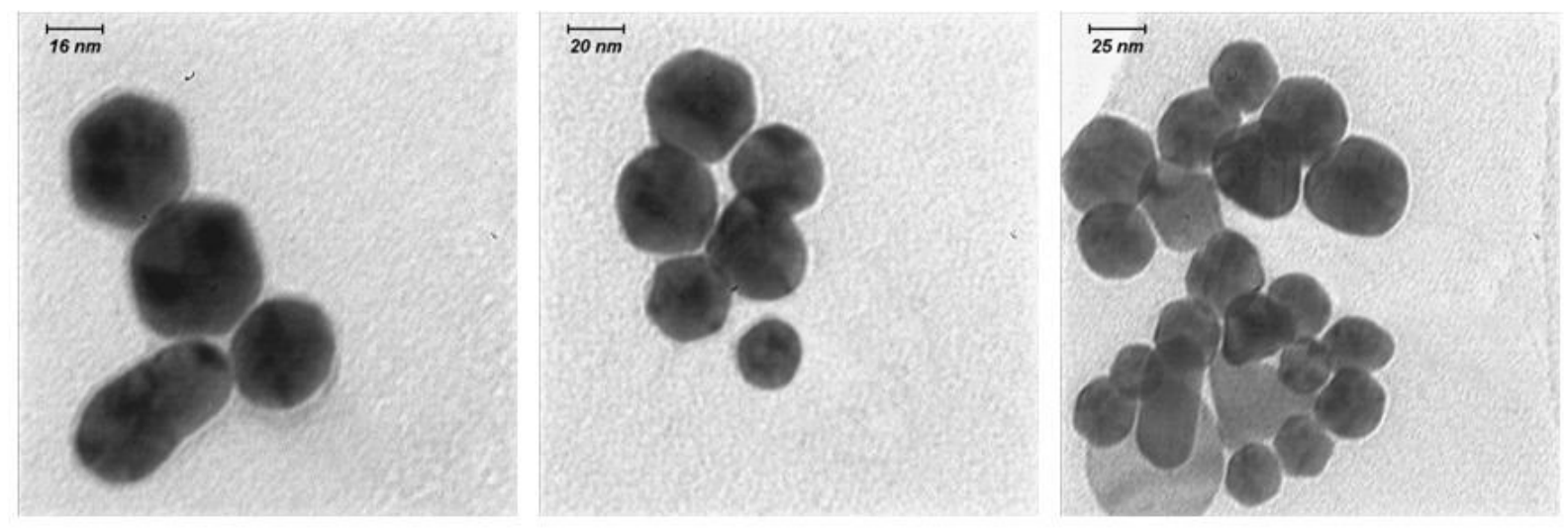

Fig. 2. TEM images of synthesized Au NPs after 45 min irradiation. 
increasing the Preyssler acid in the reaction, smaller Au NPs should be obtained. But, as shown in Fig. 4, the size of synthesized NPs exhibited a contrary trend. It is clear from the growth mechanism of the nanoparticles that nucleation and growth rates at the initial stage of chemical reaction would determine the final size of the particles [5]. In our reaction, increasing Preyssler acid (at constant $\mathrm{HAuCl}_{4}$ concentration) enhances the reduction rate, whereas the growth rate decreases at the same time due to the stabilizing role of Preyssler acid. As a result, the formation of smaller nanoparticles could be expected. The reason for the opposing trend of larger Au NPs might be the higher coverage of Preyssler polyanions on the exterior surface of $\mathrm{Au}$ NPs at higher Preyssler concentrations.

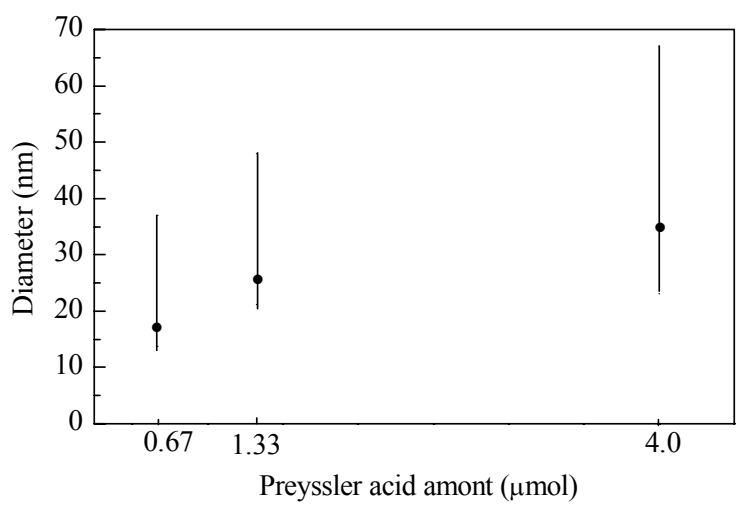

Fig. 4. Effect of Preyssler acid on the Au NP size after 45 min irradiation. Other conditions: $2 \mathrm{ml}$ propan-2-ol, $1 \mathrm{mmol} / \mathrm{L} \mathrm{HAuCl}_{4}$.

In order to compare Preyssler acid with other POMs, we have selected Keggin and Dawson structures. Under the optimum conditions, the two other POMs structures, i.e. $\mathrm{H}_{3}\left[\mathrm{PW}_{12} \mathrm{O}_{40}\right]$ (Keggin type) and $\mathrm{H}_{6}\left[\mathrm{P}_{2} \mathrm{~W}_{18} \mathrm{O}_{62}\right]$ (Dawson type), were used as reducing agent and the results were compared with Preyssler acid (see Fig. 5). As indicated in Fig. 5, the activity of the POMs decreased in the following order: $\mathrm{H}_{14}\left[\mathrm{NaP}_{5} \mathrm{~W}_{30} \mathrm{O}_{110}\right]>\mathrm{H}_{6}\left[\mathrm{P}_{2} \mathrm{~W}_{18} \mathrm{O}_{62}\right]>\mathrm{H}_{3}\left[\mathrm{PW}_{12} \mathrm{O}_{40}\right]$. The best result was observed using Preyssler acid as a reducing agent.

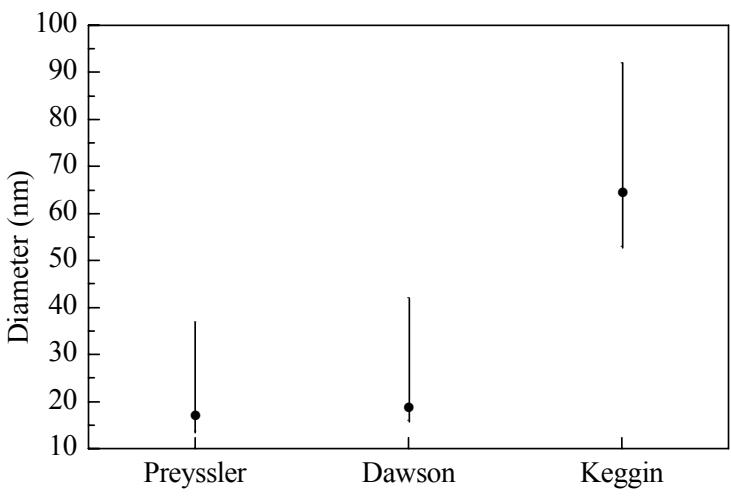

Fig. 5. Effect of POM structures on the $\mathrm{Au}$ NP size after $45 \mathrm{~min}$ irradiation. Other conditions: $2 \mathrm{ml}$ propan-2-ol, $1 \mathrm{mmol} / \mathrm{L} \mathrm{HAuCl}_{4}$.

\subsection{Photocatalytic activity of Au nanoparticles}

For investigating the catalytic performance of these $\mathrm{Au}$ NPs, they were employed in the photodegradation of $\mathrm{MeO}$, a model azo dye. The results are shown in Fig. 6. The absorbance of the solution was monitored in seven intervals up to $40 \mathrm{~min}$. A significant decrease in the absorbance bands can be observed with a decolorization degree of $95 \%$ after $40 \mathrm{~min}$. The reduction of the absorbance is a function of time in the presence of Au NPs.

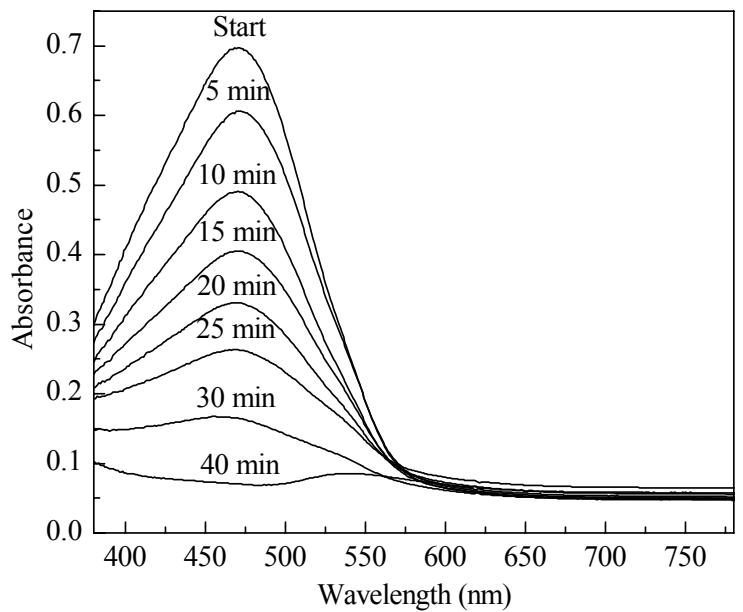

Fig. 6. Catalytic photodegradation of $\mathrm{MeO}$ in the presence of $\mathrm{Au}$ NPs.

The degree of azodye decolorization was calculated according to the following equation:

$$
C=\left(A_{0}-A_{t}\right) / A_{0} \times 100 \%
$$

where $C$ is the decolorization degree, $A_{0}$ is the initial absorbance of the $\mathrm{MeO}$ solution, and $A_{t}$ is the absorbance of the $\mathrm{MeO}$ solution after photocatalysis.

The pseudo-first-order rate constants were calculated from the plot of $\ln \left(A_{t} / A_{0}\right)$ versus time. From Fig. 7, the pseudo-first-order rate constant of $5.1 \times 10^{-2}$ was obtained. The gold nanoparticles can be separated by centrifugation and could be recycled in the reaction.

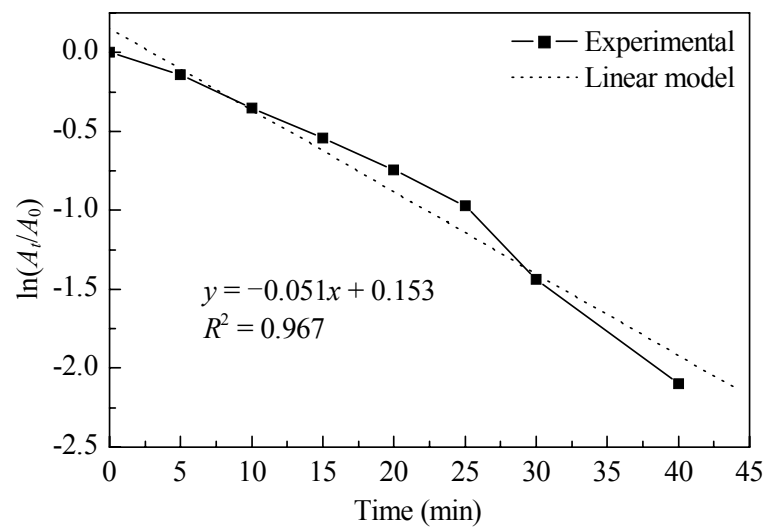

Fig. 7. Plot of $\ln \left(A_{t} / A_{0}\right)$ versus time for $\mathrm{MeO}$ photodegradation. 


\section{Conclusions}

The synthesis of gold NPs was carried out by photolysis of a deaerated solution of $\mathrm{Au}(\mathrm{III}) /$ Preyssler acid/propan-2-ol using inexpensive and easily prepared Preyssler acid as green reducing agent and stabilizer. By increasing the Preyssler acid amount, larger NPs were prepared. The comparison between different POMs has shown that the synthesized $\mathrm{Au}$ NPs are smaller and more uniform if Preyssler acid $\left(\mathrm{H}_{14}\left[\mathrm{NaP}_{5} \mathrm{~W}_{30} \mathrm{O}_{110}\right]\right)$ is used. To the best of our knowledge, this type of POM was not previously used. The synthesized nanoparticles have shown catalytic activity for the photodegradation of $\mathrm{MeO}$ with pseudo-first-order kinetic behavior. The progress in this area opens a new green path for the development of a controlled synthesis procedure for other nanoparticles in the presence of Preyssler acid.

\section{References}

1 Katsoulis D E. Chem Rev, 1998, 98: 359

2 Heravi M M, Bamoharram F F, Rajabzadeh G, Seifi N, Khatami M. J Mol Catal A, 2006, 259: 213

3 Weinstock I A. Chem Rev, 1998, 98: 113

4 Hiskia A, Mylonas A, Papaconstantinou E. Chem Soc Rev, 2001, 30: 62

5 Triantis T, Troupis A, Gkika E, Alexakos G, Boukos N, Papaconstantinou E, Hiskia A. Catal Today, 2009, 144: 2

6 Bamoharram F F, Ahmadpour A, Heravi M M, Ayati A, Rashidi H, Tanhaei B. Synth Reac Inorg Met-Org Nano-Met Chem, 2011, in press

7 Hutchings G J. Catal Today, 2005, 100: 55
8 Yu Y Y, Chang S S, Lee C L, Wang C R C. J Phys Chem B, 1997, 101: 6661

9 Mandal S, Das A, Srivastava R, Sastry M. Langmuir, 2005, 21: 2408

10 Troupis A, Hiskia A, Papaconstantinou E. Angew Chem, Int Ed, 2002, 41: 1911

11 Mandal S, Selvakannan R P, Pasricha R, Sastry M. J Am Chem Soc, 2003, 125: 8440

12 Niu C, Wu Y, Wang Z, Li Z, Li R. Frontiers Chem China, 2009, 4: 44

13 Bamoharram F F, Heravi M M, Heravi M M, Meraji M. Int J Green Nanotechnol, 2009, 1: 26

14 Heravi M M, Sadjadi S, Sadjadi S, Oskooie H A, Bamoharram F F. Ultrason Sonochem, 2009, 16: 718

15 Sadjadi S, Heravi M M, Poormohammad N, Oskooie A H, Beheshtiha Y S, Bamoharram F F. Synth Commun, 2009, 39: 3119

16 Heravi M M, Javanmardi N, Oskooie H A, Baghernejad B, Heidari M, Bamoharram F F. J Chin Chem Soc, 2009, 56: 589

17 Bamoharram F F, Heravi M M, Mehdizadeh S. Synth Reac Inorg Met-Org Nano-Met Chem, 2009, 39: 746

18 Bamoharram F F, Heravi M M, Roshani M, Jahangir M, Gharib A. Appl Catal A, 2006, 302: 42

19 Bamoharram F F, Heravi M M, Roshani M, Gharib A, Jahangir M. J Mol Catal A, 2006, 252: 90

20 Alizadeh H M, Razavi H, Bamoharram F F, Hassanzadeh M K, Khoshnavazi R, Zonoz F M. Kinet Catal, 2003, 44: 524

21 Papaconstantinou E. Chem Soc Rev, 1989, 18: 1

22 Troupis A, Gkika E, Hiskia A, Papaconstantinou E. C R Chim, 2006, 9: 851

23 Sun G Y, Li Q Y, Xu R, Gu J M, Ju M L, Wang E B. J Sol Stat Chem, 2010, 183: 2609 